\title{
A Scientometric Method to Evaluate the Academic Research Performance
}

\author{
Cornel RESTEANU', Constantin POPESCU ${ }^{2}$, Madalina Ecaterina POPESCU ${ }^{3}$ \\ ${ }^{1}$ National Institute for Research and Development in Informatics - ICI Bucharest, \\ resteanu@ici.ro \\ 2 "Valahia" University, Targoviste, Romania, \\ constantinpop1967@yahoo.com \\ ${ }^{3}$ Bucharest University of Economic Studies, \\ National Scientific Research Institute for Labour and Social Protection, \\ madalina.ecaterina.popescu@gmail.com
}

\begin{abstract}
The paper presents a method for evaluating and ranking researchers affiliated with a research and development institute. The method has been applied within the Multi-Attribute Decision Making paradigm, multi-decision maker and mono-state of nature sub-paradigm. The decision-makers are several members of the institute's Scientific Council, chosen by means of ONICESCU method to make the mathematical modelling. Researchers' expertise lies in Academic Statistics, belonging to the scientometrics domain, whose weights are constructed by DEMATEL method. The evaluation of researchers uses MAUT method. By adopting the current approach, the ranking of researchers upon their scientific merit is thus made possible.
\end{abstract}

Keywords: Scientometrics, Scientific Merit, Researchers Evaluation and Ranking, Multi-Attribute Decision Making, ONICESCU, DEMATEL, MAUT Methods.

\section{Introduction}

The topic of Scientometrics was first introduced by Nalimov in 1969 [8]. Since then, there has been a growing interest towards its practical applications, as confirmed by the vast international activity in the field.

Nowadays there are several professional organizations dedicated to this field (such as International Society of Scientometrics and Informetrics (ISSI) or SciBiolMed), as well as scientific journals (Scientometrics, Journal of Scientometric Research, Journal of Informetrics), and international conferences (The 15th ISSI International Conference „Future of scientometrics”. June 29 - July 4, 2015, Istanbul, Turcia). Also there are even commercial enterprises that develop scientometric software.

The term of Scientometrics can broadly be described as the study of measuring science, technology and innovation. In practice, any search engine that uses data mining techniques can now compute a researcher's $h$ index. However, not all searches compute the same $h$ index value for the same researcher.

Actually, we are now facing the problem that there is no single metric to evaluate a researcher. It may be impact factor, $\mathrm{H}$-index, gindex or RG score. For instance, if a researcher publishes lots of papers in low impact factor journals it may end up with limited impact on science. On the other hand, if a researcher aims high impact factor journals, he/she may end up with very few papers published because of the high rejection rate of high profile journals. Thus, the research community has not so far agreed on a clear type of score and lots of criticisms are addressed to every existing assessment scheme used to evaluate the performance of the researchers.

Despite the growing interest on the topic of Scientometrics, little has been written so far at national level. Thus, we will try to fill in this gap by presenting in this paper a novel scientometric method for highlighting the researchers' value. An evaluation and ranking algorithm combines three Multi-Attribute Decision Making (MADM) [10], [11] methods in a very effective manner so as to ensure a clear researchers' raking based on their scientific merit.

\section{Problem and Model}

In this section we present a problem belonging to the topic of Evaluating and Ranking. The case of a fictive research institute will be considered under investigation when describing the associated model. The mathematical form of the model will thoroughly be presented 
through this section. Obviously, depending on the data specificity and the problem's dimensions, the model can be configured accordingly so that it solves a broad variety of evaluation and ranking applications.

\subsection{Evaluation - ranking problem}

Let's consider the case of a research institute with 23 researchers, besides analysts, programmers and administrative staff. Its Scientific Council is made up of 7 distinguished researchers that often compute the institute's researchers hierarchy based on Google Scholar's H or / and I10 index. However, this practice has led to criticism as it is not considered to be the most accurate manner to appreciate the researchers' scientific value. It presents itself with several drawbacks, out of which data incompleteness and an approach that has the fault of being too simplistic are the most obvious ones.

Thus, we present an evaluation - ranking model that takes into consideration a larger set of indicators for evaluating and ranking the researchers' scientific performance.

The data base, named "Researchers Scientific results" will consist of main entities with the adjacent attributes refering: administration, access rights, security, pyramid style institute's structure and main attributes for researchers' evaluation, such as: name, scientific papers, citations, research areas, journals, proceedings, impact factors, statistic indicators etc. There will also be other entities whose attributes will enable the database to be a relational one.

Besides the main function of such a database, that is calculating the scientometric indicators, the associated programs will also solve an evaluation and ranking model able to provide a synthetic indicator named the scientific merit indicator.

The evaluation - ranking model belongs to the MADM field and it is similar to model given in [1].

It has the following elements:

1. $S C-$ a discrete non void and finite set, containing the Scientific Council members.

$S C=\{\operatorname{scm}(k) \mid k \in \overline{1, \mathrm{~K}}\}$, where $\mathrm{K}=\# S C$, every $s c m(k)$ element being characterized by:

- scm_c(k)-Scientific Council member's code;
- scm_n(k)-Scientific Council member's name;

- scm_w(l) - Scientific Council member's weight. By $S C W=\left\{s c m \_w(k) \mid k \in \overline{1, \mathrm{~K}}\right\}$ one denotes the vector of Scientific Council members' weights.

2. $E V-$ a discrete non void and finite set, with $E V \subset S C$, containing those Scientific Council members elected as experts for certain assignments in modelling and solving the evaluation - ranking model.

$E V=\{\operatorname{evm}(l) \mid l \in \overline{1, \mathrm{~L}}\}$, where $\mathrm{L}=\# E V$, every evm(l) element being characterized by:

- evm_c(l) - evaluation expert's code with $\left\{e v \bar{m}_{-} c(l) \mid l \in \overline{1, L}\right\} \subset\left\{s c m_{-} c(k) \mid k \in \overline{1, \mathrm{~K}}\right\}$;

- evm_n(l) - evaluation expert's name with $\left\{e v \bar{m}_{-} n(l) \mid l \in \overline{1, \mathrm{~L}}\right\} \subset\{s c m+n(k) \mid k \in \overline{1, \mathrm{~K}}\}$;

- evm_a(l) - evaluation expert's assignment;

- evm_w(l) - evaluation expert's weight. By $E V \bar{W}=\{$ evm_w $(l) \mid l \in \overline{1, \mathrm{~L}}\} \quad$ one denotes the vector of experts' weights.

3. $I R-$ a discrete non void and finite set of institute's researchers. They are subject to evaluation and ranking processes.

$I R=\{\operatorname{ir}(i) \mid i \in 1, \mathrm{I}\}$, where $\mathrm{I}=\# I R$, every $\operatorname{ir}(i)$ element being characterized by:

- ir_c(i) - researcher's code;

- ir_n(i) - researcher's name;

- ir_d(i) - researcher's short CV;

- ir_merit(i) - researcher's scientific merit.

4. $A S$ - a discrete non void and finite set of academic statistics. They will be the discriminators in the process of evaluating and ranking the researchers.

$A S=\{a s(j) \mid j \in \overline{1, J}\}$, where $\mathrm{J}=\# A S$, every as $(j)$ element being characterized by:

- $a s_{-} c(j)$ - academic statistic's code;

- as_n(j) - academic statistic's name;

- as_d(j) - academic statistic's short description;

- as_e(j) - academic statistic's expression mode (cardinal / ordinal / Boolean / fuzzy / random variable);

- as_lo(j), as_up(j) - academic statistic variations' limits;

- as_se(j) - academic statistic's sense, that is "ascending", abbreviated "A", if as $(j)$ is considered better for higher values, or "descending", abbreviated " $\mathrm{D}$ ", if as $(j)$ is considered better for smaller values; 
- $a s \_w(j)$ - academic statistic's absolute weight with the properties: $0<a s_{-} w(j)<1 \quad(\forall) j \in \overline{1, J} \quad$ and $\sum_{j=1}^{J} a s_{-} w(j)=1$.

$A S W=\left\{a s_{-} w(j) \mid j \in \overline{1, J}\right\}$ is the vector of academic statistics' absolute weights.

- $a s i_{j_{1} j_{2}}^{l}, l \in \overline{1, \mathrm{~L}}, j_{1}, j_{2} \in \overline{1, \mathrm{~J}}$ - one to one academic statistics' influences in the opinion of evm(l) expert. Thus, we understand by $A S I^{l}=\left\{a s i_{j_{1} j_{2}}^{l} \mid l \in \overline{1, \mathrm{~L}}\right.$, $\left.j_{1}, j_{2} \in \overline{1, J}\right\}$ the 3-dimension massive containing those influences.

5. Decision matrix - a 2-dimension ( $\mathrm{I} \times \mathrm{J}$ ) matrix referring to the relation between the $I R$ and $A S$ sets. $I R_{-} A S=\left\{i r_{-} a s(i, j) \mid\right.$ $i \in \overline{1, \mathrm{I}}, j \in \overline{1, J}\}$, where every $i r \_a s(i, j)$ is the $j$ - academic statistic's value corresponding to the $i$-institute's researcher.

In this moment, the multiple decision-makers MADM model is entirely defined. The goals in solving the problems generated upon this multiple decision-makers model are:

- Researchers' evaluation, i.e. to compute its scientific synthetic indicator, the scientific merit, starting from its analytical academic statistics;

- Researchers' ranking upon their scientific merit.

\subsection{Configuring the model}

To configure the model means to specify the dimensions and the data for all its entities. Thus, we obtain:

1. SC - containing the Scientific Council members, which in our case are 7 , so $\mathrm{K}=7$;

2. $E V$ - containing 3 members of Scientific Council chosen as the most suitable experts to be involved in the evaluation and ranking model. In consequence $\mathrm{L}=3$;

3. IR - containing the institute's researchers in number of 23 , so $\mathrm{I}=23$.

4. $A S$ - containing the chosen academic statistics. We assume that the Scientific Council members agreed on the following:

Publication - number of all papers published in journals,
Direct Impact - weighted average by journals impact factor of all papers,

Citations - number of citation published in journals,

Reaction Impact - weighted average by citing journals impact factor of all citations papers,

$H$ index - when $h$ of $N$ published papers have at least $h$ citations each, and the other $(N-h)$ papers have less than $h$ citations each,

Diversity - number of different research fields chosen for publishing,

Sociability - co-authors number,

Longevity - the publishing year of the last paper minus the publishing year of the first paper,

New star - number of all papers published in journals in the condition; $1<=$ Longevity $<=5$ and Publication $>=$ Longevity. The New star indicator is not included in the model, but it will be computed to complete the list of academic statistics. Therefore $\mathrm{J}=8$.

The academic statistics are expressed in integer or real numbers. The evaluation sense is ascending. The experts must express the one to one influences between academic statistics. For this, theoretically, they have a standard scale: 0 $=$ null, $1=$ small, $2=$ medium, $3=$ big, $4=$ very big. In practice, the experts' appreciations must fall in some influences' sub-intervals established by previous analysis made by statistical and benchmarking - Kiviat techniques. In the following, one presents these influences intervals / sub-intervals:

- For as $(1) \rightarrow$ as $(2) \in(2,3)$, as $(3) \in(2,3,4)$, as $(4) \in(1,2,3)$, as $(5) \in(3,4)$, as $(6) \in(0$, $1,2)$, as $(7) \in(2,3,4)$, as $(8) \in(2,3,4)$;

- For as $(2) \rightarrow$ as $(1) \in(3,4)$, as $(3) \in(2,3,4)$, as(4) $\in(3,4)$, as (5) $\in(1,2,3)$, as (6) $\in(0$, $1,2,3)$, as $(7) \in(1,2,3,4)$, as $(8) \in(0,1,2$, $3,4)$;

- For as(3) $\rightarrow$ as $(1) \in(3,4)$, as $(2) \in(1,2,3$, 4), as(4) $\in(2,3,4)$, as (5) $\in(2,3,4)$, as (6) $\in(0,1,2)$, as $(7) \in(2,3,4)$, as $(8) \in(2,3$, 4);

- For as(4) $\rightarrow$ as $(1) \in(3,4)$, as $(2) \in(3,4)$, as $(3) \in(2,3,4)$, as $(5) \in(3,4)$, as $(6) \in(0,1$, 2), as $(7) \in(2,3,4)$, as $(8) \in(2,3,4)$;

- For $a s(5) \rightarrow$ as $(1) \in(2,3,4)$, as $(2) \in(1,2$, $3,4)$, as(3) $\in(2,3,4)$, as $(4) \in(2,3,4)$, as $(6) \in(0,1,2,3)$, as $(7) \in(1,2,3,4)$, as $(8) \in(2,3,4)$; 
- For as(6) $\rightarrow$ as $(1) \in(2,3,4)$, as $(2) \in(0,1$, $2,3,4)$, as $(3) \in(1,2,3)$, as $(4) \in(0,1,2$, $3)$, as $(5) \in(0,1,2)$, as(7) $\in(2,3,4)$, as $(8)$ $\in(1,2,3,4)$;

- For $\operatorname{as}(7) \rightarrow a s(1) \in(2,3,4)$, as $(2) \in(2,3$, 4), as(3) $\in(2,3,4)$, as $(4) \in(1,2,3,4)$, as $(5) \in(0,1,2,3,4)$, as $(6) \in(0,1,2,3,4)$, as $(8) \in(0,1,2,3,4)$;

- For as $(8) \rightarrow$ as $(1) \in(2,3,4)$, as $(2) \in(2,3$, 4), as(3) $\in(2,3,4)$, as $(4) \in(1,2,3,4)$, as $(5) \in(0,1,2,3,4)$, as $(6) \in(0,1,2,3,4)$, as $(7) \in(0,1,2,3,4)$;

One can notice that sometimes the values' range of influences is restrained but there are a lot of cases in which the experts do not receive any valuable information for their appreciations.

5. IR_AS - contains ir_as $(i, j)$, the bonds between researchers and their academic statistics, with $i \in \overline{1,23}$ and $j \in \overline{1,7}$.

\section{Evaluation - Ranking Algorithm}

The evaluation and ranking algorithm is a complex one and its execution consists in three stages with multiple steps.

The algorithm is based on three MADM methods: ONICESCU [9], DEMATEL (DEcision MAking Trial and Evaluation Laboratory) [5] and MAUT (Multi-Attribute Utility Theory) [2], [3], [4], [7]. It is given in its general form but, in order to make it more comprehensible, we also present the computing results for the configured model.

\subsection{Stage 1 (ONICESCU)}

One computes $S C W=\left\{s c m \_w(k) \mid k \in 1, \mathrm{~K}\right\}$ and on this base one decides which experts from the Scientific Council are appointed with the model description and solving the problems developed on it. For experts, one computes $E V W=\left\{e v m_{-} w(l) \mid l \in 1, \mathrm{~L}\right\}$.

\section{Step 1.1}

It is presumed that the persons in $S C$ must have a fair evaluation on the hierarchy of persons in $S C$, obviously from the point of view of scientometrics and academic statistics knowledge. This hierarchy must be expressed by them under conditions of independence. Consequently, the Scientific Council members' absolute weights will be correctly computed and the choice of experts will be beyond criticism.

Let's place

$\left(s c m_{k 1}, s c m_{k 2}\right):\{1, \ldots K\} \times\{1, . . K\} \rightarrow N^{*}$

be the function associating the place of Scientific Council member $s c m(k 1)$ in the ranking induced by the Scientific Council member $\operatorname{scm}(k 2), \forall k 1, k 2 \in \overline{1, \mathrm{~K}}$. The matrix of places generated by this function is Place_scm_scm $=(\operatorname{place}(k 1, k 2))_{\substack{k 1 \in \overline{1, \mathrm{~K}} \\ k 2 \in \overline{\mathrm{I}} \mathrm{K}}}$.

See Table 1.

Step 1.2

Considering nocc_scm $(k, m)$ as the number of occurrences of the Scientific Council member $s c m(k)$ on place $m$, the matrix Nocc_scm $=(\text { nocc_scm }(k, m))_{k, m \in 1, \mathrm{~K}}$ will be constructed.

The matrix is computed from the matrix Place_scm_scm upon the following algorithm. Fill in the Nocc_scm matrix with zeroes. For $\forall k \in \overline{1, \mathrm{~K}}, n \in \overline{1, \mathrm{~K}}$ one makes $m=\operatorname{place}(k, n) \quad$ and then computes nocc_scm $(k, m)=$ nocc $\_s c m(k, m)+1$. See Table 2.

Table 1. Scientific Council members ranking by themselves

\begin{tabular}{|c|c|c|c|c|c|c|c|}
\hline $\begin{array}{l}\text { Scientific Council } \\
\text { members' ranking }\end{array}$ & $\begin{array}{l}\mathrm{SC} \mathrm{m} \mathrm{m}_{1} \\
\text { place }\end{array}$ & $\begin{array}{l}\mathrm{SC} \mathrm{m}_{2} \\
\text { place }\end{array}$ & $\begin{array}{l}\mathrm{SC} \mathrm{m}_{3} \\
\text { place }\end{array}$ & $\begin{array}{l}\mathrm{SC} \mathrm{m}_{4} \\
\text { place }\end{array}$ & $\begin{array}{l}\mathrm{SC} \mathrm{m}_{5} \\
\text { place }\end{array}$ & $\begin{array}{l}\mathrm{SC} \mathrm{m}_{6} \\
\text { place }\end{array}$ & $\begin{array}{l}\mathrm{SC} \mathrm{m}_{7} \\
\text { place }\end{array}$ \\
\hline $\mathrm{SC} \mathrm{m} \mathrm{m}_{1}$ & 2 & 1 & 5 & 3 & 4 & 7 & 6 \\
\hline $\mathrm{SC} \mathrm{m}_{2}$ & 3 & 2 & 5 & 1 & 6 & 4 & 7 \\
\hline $\mathrm{SC} \mathrm{m}_{3}$ & 3 & 1 & 5 & 2 & 7 & 6 & 4 \\
\hline $\mathrm{SC} \mathrm{m}_{4}$ & 1 & 2 & 7 & 3 & 4 & 5 & 6 \\
\hline $\mathrm{SC} \mathrm{m}_{5}$ & 1 & 4 & 5 & 2 & 6 & 7 & 3 \\
\hline $\mathrm{SC} \mathrm{m} 6$ & 1 & 2 & 6 & 3 & 4 & 7 & 5 \\
\hline $\mathrm{SC} \mathrm{m}_{7}$ & 2 & 3 & 5 & 1 & 4 & 6 & 7 \\
\hline
\end{tabular}


Step 1.3

One computes the evaluation of the Scientific Council members upon the synthetic score's formula:

$s s(k)=\sum_{m=1}^{\mathrm{K}} 1 / 2^{m}$ nocc_scm $(k, m), \quad \forall k \in \overline{1, \mathrm{~K}}$

Now,

$$
s c m_{-} w(k)=\frac{s s(k)}{\sum_{k=1}^{\mathrm{K}} s s(k)}, \quad \forall k \in 1, \mathrm{~K}
$$

the Scientific Council members' weights and their vector $S C W=\left\{s c m_{-} w(k) \mid k \in \overline{1, K}\right\}$ are well defined.

\section{Remarks:}

- $\mathrm{SC} \mathrm{m}_{1} \mathrm{SC} \mathrm{m}_{2}$ and $\mathrm{SC} \mathrm{m}_{4}$ are the most influent Scientific Council members in scientometrics and academic statistics. In consequence they will be designated to define and solve the evaluation - ranking model;
- New weights are computed for them with a similar formula given above.

See Table 3.

\subsection{Stage 2 (DEMATEL)}

The Scientific Council members, chosen as experts in scientometrics and academic statistics, determine the academic statistics' absolute weights starting from one to one influence of academic statistics. This operation must be accomplished under the following two conditions:

- The experts work independently;

- In the appreciation problem, how the academic statistic ' $j_{1}$ ' influences the academic statistic ' $j_{2}$ ', every expert will use the same influences intervals / subintervals given at paragraph 2.2.

\section{Step 2.1}

The academic statistics' relative influences are not possible to be entirely scientifically computed. Therefore, it is correct that one

Table 2. Scientific Council members' analytic scores

\begin{tabular}{|c|c|c|c|c|c|c|c|}
\hline $\begin{array}{c}\text { Number of Positions in } \\
\text { rankings }\end{array}$ & $\begin{array}{c}\text { 1-st } \\
\text { place }\end{array}$ & $\begin{array}{c}\text { 2-nd } \\
\text { place }\end{array}$ & $\begin{array}{c}\text { 3-rd } \\
\text { place }\end{array}$ & $\begin{array}{c}\text { 4-th } \\
\text { place }\end{array}$ & $\begin{array}{c}5 \text {-th } \\
\text { place }\end{array}$ & $\begin{array}{c}\text { 6-th } \\
\text { place }\end{array}$ & $\begin{array}{c}\text { 7-th } \\
\text { place }\end{array}$ \\
\hline $\mathrm{SC} \mathrm{m}_{1}$ & 3 & 2 & 2 & 0 & 0 & 0 & 0 \\
\hline $\mathrm{SC} \mathrm{m}_{2}$ & 2 & 3 & 1 & 1 & 0 & 0 & 0 \\
\hline $\mathrm{SC} \mathrm{m}$ & 0 & 0 & 0 & 0 & 5 & 1 & 1 \\
\hline $\mathrm{SC} \mathrm{m}_{4}$ & 2 & 2 & 3 & 0 & 0 & 0 & 0 \\
\hline $\mathrm{SC} \mathrm{m}_{5}$ & 0 & 0 & 0 & 4 & 0 & 2 & 1 \\
\hline $\mathrm{SC} \mathrm{m}_{6}$ & 0 & 0 & 0 & 1 & 1 & 2 & 3 \\
\hline $\mathrm{SC} \mathrm{m}_{7}$ & 0 & 0 & 1 & 1 & 1 & 2 & 2 \\
\hline
\end{tabular}

Table 3. Scientific Council members' synthetic score and experts' selection

\begin{tabular}{|c|c|c|c|c|}
\hline $\begin{array}{c}\text { Scientific Council } \\
\text { members' score and } \\
\text { weights }\end{array}$ & Synthetic score & Weight & $\begin{array}{c}\text { Chosen Scientific } \\
\text { Council members as } \\
\text { experts }\end{array}$ & $\begin{array}{c}\text { Recomputed } \\
\text { weight }\end{array}$ \\
\hline $\mathrm{SC} \mathrm{m}_{1}$ & 2.25 & 0.32396 & $*$ & 0.371134 \\
\hline $\mathrm{SC} \mathrm{m}_{2}$ & 1.9375 & 0.278965 & $*$ & 0.319588 \\
\hline $\mathrm{SC} \mathrm{m}_{3}$ & 0.179688 & 0.025872 & & \\
\hline $\mathrm{SC} \mathrm{m}_{4}$ & 1.875 & 0.269966 & $*$ & 0.309278 \\
\hline $\mathrm{SC} \mathrm{m}_{5}$ & 0.289063 & 0.04162 & & \\
\hline $\mathrm{SC} \mathrm{m}_{6}$ & 0.148438 & 0.021372 & & \\
\hline $\mathrm{SC} \mathrm{m}_{7}$ & 0.265625 & 0.038245 & & \\
\hline Weights sum & & 1 & & \\
\hline
\end{tabular}


appeals to the experts' knowledge that is based on practical experience. One supposes that the three experts, chosen from Scientific Council members and indexed by $l \in \overline{1, L}$, fill-in, every one upon the personal knowledge, the one to one influences of academic statistics, denoted by $a s i_{j_{1} j_{2}}^{l}$ with $j_{1}, j_{2} \in \overline{1, J}$.

These appreciations produce $\mathrm{L}$ not-negative matrices of $(\mathrm{J}, \mathrm{J})$-dimension, denoted by
$A^{l}=\left\{\operatorname{asi}_{j_{1} j_{2}}^{l} \mid l \in \overline{1, \mathrm{~L}}, j_{1}, j_{2} \in \overline{1, \mathrm{~J}}\right\}$.

One remarks that $\forall l \in \overline{1, \mathrm{~L}}, a s i_{j_{1} j_{2}}^{l}=0$, $\forall j_{1}=j_{2}$, in other words, all matrices have null-diagonals. See Tables 4, 5 and 6.

Step 2.2

One computes

$a s i_{j_{1} j_{2}}^{*}=\sum_{l=1}^{\mathrm{L}} e v m_{-} w(l) \cdot a s i_{j_{1} j_{2}}^{l}, \forall j_{1}, j_{2} \in \overline{1, \mathrm{~J}}$.

Table 4. First expert's appreciation - one to one influences of academic statistics

\begin{tabular}{|c|r|r|r|r|r|r|r|r|}
\hline $\boldsymbol{A S \boldsymbol { I } ^ { \mathbf { I } }}$ & $a_{1}$ & $a_{2}$ & \multicolumn{1}{|c|}{$a_{3}$} & $a_{4}$ & $a_{5}$ & $a_{6}$ & \multicolumn{1}{|c|}{$a_{7}$} & \multicolumn{1}{|c|}{$a_{8}$} \\
\hline$a_{1}$ & 0 & 3 & 2 & 2 & 4 & 0 & 4 & 4 \\
\hline$a_{2}$ & 3 & 0 & 3 & 3 & 4 & 2 & 1 & 1 \\
\hline$a_{3}$ & 3 & 3 & 0 & 3 & 3 & 0 & 2 & 2 \\
\hline$a_{4}$ & 3 & 3 & 2 & 0 & 4 & 2 & 2 & 3 \\
\hline$a_{5}$ & 2 & 2 & 2 & 3 & 0 & 0 & 3 & 1 \\
\hline$a_{6}$ & 2 & 2 & 1 & 2 & 2 & 0 & 4 & 3 \\
\hline$a_{7}$ & 1 & 2 & 3 & 1 & 0 & 4 & 0 & 0 \\
\hline$a_{8}$ & 1 & 2 & 3 & 2 & 0 & 2 & 1 & 0 \\
\hline
\end{tabular}

Table 5. Second expert's appreciation - one to one influences of academic statistics

\begin{tabular}{|l|r|r|r|r|r|r|r|r|}
\hline $\boldsymbol{A S \boldsymbol { I } ^ { 2 }}$ & $a_{1}$ & $a_{2}$ & $a_{3}$ & $a_{4}$ & $a_{5}$ & $a_{6}$ & \multicolumn{1}{|c|}{$a_{7}$} & \multicolumn{1}{c|}{$a_{8}$} \\
\hline$a_{1}$ & 0 & 3 & 3 & 1 & 3 & 1 & 2 & 3 \\
\hline$a_{2}$ & 3 & 0 & 4 & 3 & 2 & 2 & 2 & 1 \\
\hline$a_{3}$ & 2 & 2 & 0 & 3 & 3 & 0 & 2 & 2 \\
\hline$a_{4}$ & 3 & 3 & 2 & 0 & 4 & 2 & 2 & 3 \\
\hline$a_{5}$ & 2 & 3 & 2 & 3 & 0 & 0 & 1 & 3 \\
\hline$a_{6}$ & 2 & 3 & 1 & 2 & 2 & 0 & 4 & 3 \\
\hline$a_{7}$ & 2 & 3 & 3 & 2 & 0 & 4 & 0 & 1 \\
\hline$a_{8}$ & 3 & 2 & 3 & 2 & 0 & 1 & 0 & 0 \\
\hline
\end{tabular}

Table 6. Third expert's appreciation - one to one influences of academic statistics

\begin{tabular}{|c|r|r|r|r|r|r|r|r|}
\hline $\boldsymbol{A S I}^{3}$ & $a_{1}$ & $a_{2}$ & $a_{3}$ & $a_{4}$ & $a_{5}$ & $a_{6}$ & \multicolumn{1}{|c|}{$a_{7}$} & \multicolumn{1}{|c|}{$a_{8}$} \\
\hline$a_{1}$ & 0 & 2 & 3 & 3 & 3 & 0 & 3 & 4 \\
\hline$a_{2}$ & 3 & 0 & 4 & 3 & 4 & 2 & 2 & 1 \\
\hline$a_{3}$ & 3 & 1 & 0 & 3 & 4 & 0 & 1 & 2 \\
\hline$a_{4}$ & 3 & 4 & 2 & 0 & 3 & 1 & 2 & 2 \\
\hline$a_{5}$ & 2 & 3 & 2 & 4 & 0 & 0 & 3 & 3 \\
\hline$a_{6}$ & 4 & 1 & 1 & 2 & 2 & 0 & 4 & 4 \\
\hline$a_{7}$ & 2 & 2 & 3 & 2 & 0 & 4 & 0 & 1 \\
\hline$a_{8}$ & 2 & 3 & 3 & 2 & 1 & 4 & 0 & 0 \\
\hline
\end{tabular}


These compose a $(\mathrm{J}, \mathrm{J})$-dimension matrix, named $A S I^{*}=\left\{a s i_{j_{1}, j_{2}}^{*}, \mid j_{1}, j_{2} \in \overline{1, J}\right\}$. This weighted average matrix is also called the initial direct relation matrix. It makes a synthesis of experts' opinions and shows the initial direct effects that an academic statistic exerts on and receives from other academic statistics. See Table 7.

\section{Step 2.3}

Since for the academic statistic $j_{l}$ of the matrix $A S I^{*}, \quad \sum_{j_{2}=l}^{\mathrm{J}} a s i_{j_{1} j_{2}}^{*}$ represents the total direct influence that the academic statistic $j_{1}$ gives to all other academic statistics, $\underset{l \leq j_{1} \leq \mathrm{J}}{\max } \sum_{j_{2}=1}^{\mathrm{J}} a s i_{j_{1} j_{2}}^{*}$ represents the total direct influence given to all other academic statistics by the most influent academic statistic. Likewise, since $\sum_{j_{1}=1}^{\mathrm{J}} a s i_{j_{1} j_{2}}^{*}$ represents the total direct influence received by academic statistic $j_{2}$ from all other academic statistics, $\max _{l \leq j_{2} \leq \mathrm{J}} \sum_{j_{1}=1}^{\mathrm{J}} a s i_{j_{1} j_{2}}^{*}$ represents the total of direct influence received by the most influenced academic statistic. One takes $s=\max \left(\max _{1 \leq j_{1} \leq \mathrm{J}} \sum_{j_{2}=1}^{\mathrm{J}} a s i_{j_{1} j_{2}}^{*}, \max _{1 \leq j_{2} \leq \mathrm{J}} \sum_{j_{1}=1}^{J} a s i_{j_{1} j_{2}}^{*}\right) \quad$ as scaling factor for $A S I^{*}$ matrix. Dividing each element of $A S I^{*}$ by the ' $s$ ' scalar, one obtains $D=$ nomalized $A S I^{*}=1 / s \cdot A S I^{*}$ a matrix with each element between zero and one.

See Table 8.

Step 2.4

One notices that

$$
c_{j_{2}}=\sum_{j_{1}=1}^{\mathrm{J}} d_{j_{1} j_{2}}<1, \forall j_{2} \in(1, \mathrm{~J}) \text {. }
$$

Table 7. Initial weighted average matrix

\begin{tabular}{|l|r|c|c|r|r|r|c|c|}
\hline $\boldsymbol{A S I}^{4}$ & \multicolumn{1}{|c|}{$a_{1}$} & $a_{2}$ & $a_{3}$ & $a_{4}$ & $a_{5}$ & $a_{6}$ & $a_{7}$ & $a_{8}$ \\
\hline$a_{1}$ & 0 & 0.896907 & 0.876289 & 0.66323 & 1.123711 & 0.106529 & 1.017182 & 1.226804 \\
\hline$a_{2}$ & 1 & 0 & 1.209622 & 1 & 1.120275 & 0.666667 & 0.542955 & 0.33333333 \\
\hline$a_{3}$ & 0.893471 & 0.687285 & 0 & 1 & 1.103093 & 0 & 0.563574 & 0.6666667 \\
\hline$a_{4}$ & 1 & 1.103093 & 0.666667 & 0 & 1.230241 & 0.563574 & 0.666667 & 0.8969073 \\
\hline$a_{5}$ & 0.666667 & 0.876289 & 0.666667 & 1.103093 & 0 & 0 & 0.786941 & 0.7525773 \\
\hline$a_{6}$ & 0.872852 & 0.670103 & 0.333333 & 0.666667 & 0.666667 & 0 & 1.333333 & 1.1030927 \\
\hline$a_{7}$ & 0.542955 & 0.773196 & 1 & 0.542955 & 0 & 1.333333 & 0 & 0.209622 \\
\hline$a_{8}$ & 0.649485 & 0.769759 & 1 & 0.666667 & 0.103093 & 0.766323 & 0.123711 & 0 \\
\hline
\end{tabular}

Table 8. Initial weighted average matrix by normalization

\begin{tabular}{|c|c|c|r|r|r|r|r|c|}
\hline $\boldsymbol{D}$ & $d_{1}$ & \multicolumn{1}{c|}{$d_{2}$} & $d_{3}$ & $d_{4}$ & $d_{5}$ & $d_{6}$ & $d_{7}$ & $d_{8}$ \\
\hline$d_{1}$ & 0 & 0.146383 & 0.143017 & 0.108244 & 0.183399 & 0.017386 & 0.166012 & 0.2002243 \\
\hline$d_{2}$ & 0.163208 & 0 & 0.19742 & 0.163208 & 0.182838 & 0.108805 & 0.088615 & 0.0544027 \\
\hline$d_{3}$ & 0.145822 & 0.112171 & 0 & 0.163208 & 0.180034 & 0 & 0.09198 & 0.1088054 \\
\hline$d_{4}$ & 0.163208 & 0.180034 & 0.108805 & 0 & 0.200785 & 0.09198 & 0.108805 & 0.1463825 \\
\hline$d_{5}$ & 0.108805 & 0.143017 & 0.108805 & 0.180034 & 0 & 0 & 0.128435 & 0.1228267 \\
\hline$d_{6}$ & 0.142456 & 0.109366 & 0.054403 & 0.108805 & 0.108805 & 0 & 0.217611 & 0.1800336 \\
\hline$d_{7}$ & 0.088615 & 0.126192 & 0.163208 & 0.088615 & 0 & 0.217611 & 0 & 0.034212 \\
\hline$d_{8}$ & 0.106001 & 0.125631 & 0.163208 & 0.108805 & 0.016826 & 0.12507 & 0.020191 & 0 \\
\hline
\end{tabular}


See Table 9, and so $\lim _{n \rightarrow \infty} D^{n}=0$ where 0 is the null-matrix of (J, J)-dimension [6].

Under this condition, illustrated above,

$\lim _{n \rightarrow \infty}\left(I+D+D^{2}+D^{3}+\ldots+D^{n}\right)=(I-D)^{-1}$, where

$I$ is the unit matrix of $(\mathrm{J}, \mathrm{J})$-dimension.

The total relation matrix $T_{n}=\left\{t_{j_{1} j_{2}} \mid 1 \leq j_{1}, j_{2} \leq \mathrm{J}\right\}$ is a $(\mathrm{J}, \mathrm{J})$-dimension matrix defined by $T=\lim _{n \rightarrow \infty} T_{n}=D(I-D)^{-1}$, where

$$
\begin{aligned}
T_{n} & =D+D^{2}+D^{3}+\ldots+D^{n}= \\
& =D\left(I+D+D^{2}+\ldots+D^{n-1}\right)
\end{aligned} .
$$

See Table 10.

One computes, in the total relations' matrix, the rows' sum and the columns' sum.

Let it be:

- $\quad r=\left(r_{j_{2}}\right)_{1 \leq j_{2} \leq \mathrm{J}}$, where $r_{j_{2}}$ is the component $j_{2}$ in this vector and represents the total effect, direct and indirect, manifested by academic statistic $j_{2}$ on the rest of academic statistics;

- $c=\left(c_{j_{1}}\right)_{1 \leq j_{1} \leq \mathrm{J}}$, where $c_{j_{1}}$ is the component $j_{1}$ in this vector and represents total effect, direct and indirect, manifested by the rest of academic statistics on $j_{1}$ academic statistic.

If in the sum $\left(r_{j_{2}}+c_{j_{1}}\right)$ on takes $j_{1}=j_{2}=j$, for $j$ academic statistic, one defines one indicator for total influence on and from the rest of academic statistics. In other words, $\left(r_{j}+c_{j}\right)$ is a measure for $j$ - academic statistic's absolute weight. The academic statistics' absolute weights derived from Table 10 are presented in Table 11 and determine the vector $A S W=\left\{a s_{-} w(j) \mid j \in \overline{1, J}\right\}$. One notices that these numbers are greater than 0 and smaller or equal to 1 , their sum being equal to 1 .

\subsection{Stage 3 (MAUT)}

One composes the evaluation - ranking model transferring the necessary data from "Researchers Scientific results" data base. It

Table 9. Proofing that the above limit is the null matrix

\begin{tabular}{|c|c|c|c|c|c|c|c|c|}
\hline DCC & $d_{1}$ & $d_{2}$ & $d_{3}$ & $d_{4}$ & $d_{5}$ & $d_{6}$ & $d_{7}$ & $d_{8}$ \\
\hline$c_{j_{2}}$ & 0.918115 & 0.942793 & 0.938867 & 0.92092 & 0.872686 & 0.560852 & 0.821649 & 0.8468872 \\
\hline
\end{tabular}

Table 10. Total relations' matrix

\begin{tabular}{|c|r|r|r|r|r|r|r|c|}
\hline $\boldsymbol{T}$ & \multicolumn{1}{|c|}{$t_{1}$} & \multicolumn{1}{c|}{$t_{2}$} & \multicolumn{1}{c|}{$t_{3}$} & \multicolumn{1}{c|}{$t_{4}$} & \multicolumn{1}{c|}{$t_{5}$} & \multicolumn{1}{c|}{$t_{6}$} & \multicolumn{1}{c|}{$t_{7}$} & $t_{8}$ \\
\hline$t_{1}$ & 0.739868 & 0.892859 & 0.904815 & 0.853688 & 0.883122 & 0.480778 & 0.779118 & 0.8420338 \\
\hline$t_{2}$ & 0.91113 & 0.791832 & 0.962869 & 0.925005 & 0.926968 & 0.55507 & 0.754435 & 0.7596792 \\
\hline$t_{3}$ & 0.774903 & 0.771423 & 0.676324 & 0.802561 & 0.800885 & 0.39701 & 0.641677 & 0.6887942 \\
\hline$t_{4}$ & 0.9284 & 0.965907 & 0.919339 & 0.801871 & 0.949689 & 0.563065 & 0.781937 & 0.8469971 \\
\hline$t_{5}$ & 0.739511 & 0.787886 & 0.769506 & 0.80622 & 0.635546 & 0.403117 & 0.662778 & 0.6888125 \\
\hline$t_{6}$ & 0.838072 & 0.836063 & 0.803168 & 0.818473 & 0.787758 & 0.458296 & 0.810968 & 0.8075304 \\
\hline$t_{7}$ & 0.682761 & 0.722039 & 0.756125 & 0.683841 & 0.601447 & 0.559982 & 0.53221 & 0.5854683 \\
\hline$t_{8}$ & 0.657425 & 0.683153 & 0.719162 & 0.663478 & 0.582297 & 0.447235 & 0.510689 & 0.5136789 \\
\hline
\end{tabular}

Table 11. Academic Statistics' weights

\begin{tabular}{|c|c|c|c|c|c|c|c|c|}
\hline $\begin{array}{c}\text { Academic } \\
\text { Statistics }\end{array}$ & $a_{1}$ & $a_{2}$ & $a_{3}$ & $a_{4}$ & $a_{5}$ & $a_{6}$ & $a_{7}$ & $a_{8}$ \\
\hline Weights & 0.135049 & 0.139211 & 0.128819 & 0.140003 & 0.124508 & 0.107038 & 0.113154 & 0.1122186 \\
\hline
\end{tabular}


should be notice that, at this moment, the data base contains and the academic statistics' weights determined at Stage 2. The evaluation method takes into account the researchers' academic statistics and their weights, computing the individual scientific merits like values of a global utility function. Finally, a researchers' ranking is presented.
Step 3.1

In a table like Table 12, one writes the MADM model, with all information pending on it. The table contains two sections, data from the data base and data given at model configuration. The academic statistics are computed, for each researcher, as a sum of elementary entries in time. The $U p$ values are, viewing the values of

Table 12. Evaluation model

\begin{tabular}{|c|c|c|c|c|c|c|c|c|}
\hline $\begin{array}{l}\text { Academic } \\
\text { Statistics }\end{array}$ & $a s_{1}$ & $a s_{2}$ & $a s_{3}$ & $A s_{4}$ & $a s_{5}$ & $a_{6}$ & $a s_{7}$ & $a s_{8}$ \\
\hline Expression & $\mathrm{N}$ & $\mathrm{R}$ & $\mathrm{N}$ & $\mathrm{R}$ & $\mathrm{N}$ & $\mathrm{N}$ & $\mathrm{N}$ & $\mathrm{N}$ \\
\hline Sense & A & A & A & A & A & A & A & A \\
\hline Lo & 0 & 0 & 0 & 0 & 0 & 0 & 0 & 0 \\
\hline $\mathrm{Up}$ & 83 & 2,15 & 589 & 1.55 & 19 & 5 & 14 & 30 \\
\hline Weights & 0.135049 & 0.139211 & 0.128819 & 0.140003 & 0.124508 & 0.107038 & 0.113154 & 0.1122186 \\
\hline \multicolumn{9}{|c|}{ Researchers / Academic Statistics } \\
\hline$r_{1}$ & 83 & 1,72 & 307 & 1,20 & 17 & 5 & 12 & 30 \\
\hline$r_{2}$ & 71 & 1,27 & 423 & 0,76 & 18 & 3 & 9 & 26 \\
\hline$r_{3}$ & 78 & 2,15 & 482 & 0,80 & 15 & 6 & 8 & 23 \\
\hline$r_{4}$ & 64 & 1,65 & 589 & 1,55 & 19 & 2 & 12 & 17 \\
\hline$r_{5}$ & 63 & 1,46 & 253 & 1,22 & 16 & 3 & 11 & 15 \\
\hline$r_{6}$ & 61 & 1,45 & 264 & 1,14 & 16 & 2 & 14 & 15 \\
\hline$r_{7}$ & 52 & 1,24 & 224 & 0,87 & 15 & 3 & 13 & 15 \\
\hline$r_{8}$ & 48 & 0,78 & 207 & 0,65 & 15 & 3 & 8 & 15 \\
\hline$r_{9}$ & 46 & 1,23 & 208 & 1,17 & 17 & 2 & 3 & 15 \\
\hline$r_{10}$ & 39 & 1,51 & 176 & 1,46 & 12 & 3 & 11 & 14 \\
\hline$r_{11}$ & 37 & 0,76 & 153 & 0,68 & 10 & 3 & 9 & 14 \\
\hline$r_{12}$ & 34 & 1,21 & 143 & 1,05 & 12 & 2 & 9 & 14 \\
\hline$r_{13}$ & 26 & 1,76 & 120 & 1,54 & 8 & 2 & 7 & 12 \\
\hline$r_{14}$ & 25 & 1,52 & 106 & 0,87 & 7 & 2 & 5 & 12 \\
\hline$r_{15}$ & 19 & 1,27 & 76 & 0,96 & 8 & 3 & 8 & 12 \\
\hline$r_{16}$ & 15 & 1,36 & 81 & 1,12 & 6 & 2 & 4 & 10 \\
\hline$r_{17}$ & 14 & 1,29 & 97 & 0,76 & 6 & 2 & 5 & 10 \\
\hline$r_{18}$ & 12 & 1,24 & 71 & 1,12 & 6 & 2 & 4 & 8 \\
\hline$r_{19}$ & 12 & 1,16 & 84 & 1,07 & 5 & 2 & 4 & 8 \\
\hline$r_{20}$ & 9 & 0,78 & 61 & 0,65 & 4 & 2 & 2 & 6 \\
\hline$r_{21}$ & 8 & 0,76 & 59 & 0,72 & 4 & 2 & 2 & 6 \\
\hline$r_{22}$ & 6 & 1,27 & 43 & 0,85 & 2 & 1 & 2 & 5 \\
\hline$r_{23}$ & 5 & 0,83 & 37 & 0,64 & 2 & 1 & 1 & 4 \\
\hline
\end{tabular}


Sense, maximum on each academic statistics' column. In these circumstances, the model validation is not necessary.

Step 3.2

One computes $i r_{-} a s_{j}^{+}=\max _{1 \leq i \leq I} i r_{-} a s(i, j)$, $\forall j \in \overline{1, \mathrm{~J}}$ and normalizes the values of matrix $I R \_A S$ taking

$i r_{-} a s(i, j)=i r_{-} a s(i, j) / i r_{-} a s_{j}^{+}$, $\forall i \in \overline{1, \mathrm{I}}, \forall j \in \overline{1, \mathrm{~J}} \cdot$
Now, every element ir_as $(i, j)$ of matrix $I R \_A S$ with $i \in \overline{1, \mathrm{I}}$ and $j \in \overline{1, \mathrm{~J}}$ is multiplied with the corresponding element $a s \_w(j)$ of vector $A S W$ with $j \in \overline{1, \mathrm{~J}}$ obtaining analytical merits of researchers.

Finally, $\forall i \in \overline{1, \mathrm{I}}$, one computes

$$
\sum_{j=1}^{\mathrm{J}} a s(i, j)=\text { scientific_merit }(i),
$$

the synthetic merits of researchers.

See Table 13.

Table 13. Evaluation model results

\begin{tabular}{|c|c|c|c|c|c|c|c|c|c|}
\hline \multicolumn{9}{|c|}{ Researchers / Analytical merits } & \multirow{2}{*}{$\begin{array}{c}\text { Scientific } \\
\text { synthetic } \\
\text { merit }\end{array}$} \\
\hline & $a s_{1}$ & $a s_{2}$ & $a s_{3}$ & $a s_{4}$ & $a s_{5}$ & $a s_{6}$ & $a s_{7}$ & $a s_{8}$ & \\
\hline$r_{1}$ & 0.135049 & 0.111369 & 0.067143 & 0.108389 & 0.111402 & 0.089198 & 0.096989 & 0.112219 & 0.831759 \\
\hline$r_{2}$ & 0.115524 & 0.082232 & 0.092513 & 0.068647 & 0.117955 & 0.053519 & 0.072742 & 0.097256 & 0.700387 \\
\hline$r_{3}$ & 0.126914 & 0.139211 & 0.105417 & 0.07226 & 0.098296 & 0.107038 & 0.064659 & 0.086034 & 0.799829 \\
\hline$r_{4}$ & 0.104134 & 0.106836 & 0.128819 & 0.140003 & 0.124508 & 0.035679 & 0.096989 & 0.063591 & 0.80056 \\
\hline$r_{5}$ & 0.102507 & 0.094534 & 0.055333 & 0.110196 & 0.104849 & 0.053519 & 0.088907 & 0.056109 & 0.665954 \\
\hline$r_{6}$ & 0.099253 & 0.093886 & 0.057739 & 0.10297 & 0.104849 & 0.035679 & 0.113154 & 0.056109 & 0.66364 \\
\hline$r_{7}$ & 0.084609 & 0.080289 & 0.048991 & 0.078582 & 0.098296 & 0.053519 & 0.105072 & 0.056109 & 0.605467 \\
\hline$r_{8}$ & 0.078101 & 0.050504 & 0.045273 & 0.058711 & 0.098296 & 0.053519 & 0.064659 & 0.056109 & 0.505172 \\
\hline$r_{9}$ & 0.074846 & 0.079642 & 0.045491 & 0.10568 & 0.111402 & 0.035679 & 0.024247 & 0.056109 & 0.533097 \\
\hline$r_{10}$ & 0.063457 & 0.097771 & 0.038493 & 0.131874 & 0.078637 & 0.053519 & 0.088907 & 0.052369 & 0.605026 \\
\hline$r_{11}$ & 0.060203 & 0.049209 & 0.033462 & 0.061421 & 0.065531 & 0.053519 & 0.072742 & 0.052369 & 0.448455 \\
\hline$r_{12}$ & 0.055321 & 0.078347 & 0.031275 & 0.094841 & 0.078637 & 0.035679 & 0.072742 & 0.052369 & 0.49921 \\
\hline$r_{13}$ & 0.042305 & 0.113959 & 0.026245 & 0.1391 & 0.052424 & 0.035679 & 0.056577 & 0.044887 & 0.511176 \\
\hline$r_{14}$ & 0.040677 & 0.098419 & 0.023183 & 0.078582 & 0.045871 & 0.035679 & 0.040412 & 0.044887 & 0.407712 \\
\hline$r_{15}$ & 0.030915 & 0.082232 & 0.016622 & 0.086712 & 0.052424 & 0.053519 & 0.064659 & 0.044887 & 0.43197 \\
\hline$r_{16}$ & 0.024406 & 0.088059 & 0.017715 & 0.101163 & 0.039318 & 0.035679 & 0.03233 & 0.037406 & 0.376078 \\
\hline$r_{17}$ & 0.022779 & 0.083527 & 0.021215 & 0.068647 & 0.039318 & 0.035679 & 0.040412 & 0.037406 & 0.348983 \\
\hline$r_{18}$ & 0.019525 & 0.080289 & 0.015528 & 0.101163 & 0.039318 & 0.035679 & 0.03233 & 0.029925 & 0.353758 \\
\hline$r_{19}$ & 0.019525 & 0.075109 & 0.018371 & 0.096647 & 0.032765 & 0.035679 & 0.03233 & 0.029925 & 0.340352 \\
\hline$r_{20}$ & 0.014644 & 0.050504 & 0.013341 & 0.058711 & 0.026212 & 0.035679 & 0.016165 & 0.022444 & 0.237701 \\
\hline$r_{21}$ & 0.013017 & 0.049209 & 0.012904 & 0.065034 & 0.026212 & 0.035679 & 0.016165 & 0.022444 & 0.240664 \\
\hline$r_{22}$ & 0.009763 & 0.082232 & 0.009404 & 0.076776 & 0.013106 & 0.01784 & 0.016165 & 0.018703 & 0.243988 \\
\hline$r_{23}$ & 0.008135 & 0.053742 & 0.008092 & 0.057808 & 0.013106 & 0.01784 & 0.008082 & 0.014962 & 0.181768 \\
\hline
\end{tabular}


$S O R T_{\text {_ }} D($ scientific_merit $(i), i \in \overline{1, \mathrm{I}})$ giving (scientific_merit $(i), i \in \overline{1, \sigma(\mathrm{I})})$.

The final ranking of the researchers is presented in Table 14.

Table 14. Final researchers' ranking

\begin{tabular}{|c|c|}
\hline \multicolumn{2}{|c|}{ Researchers' Ranking } \\
\hline Researchers & Merits \\
\hline$r_{1}$ & 0.831759 \\
\hline$r_{4}$ & 0.80056 \\
\hline$r_{3}$ & 0.799829 \\
\hline$r_{2}$ & 0.700387 \\
\hline$r_{5}$ & 0.665954 \\
\hline$r_{6}$ & 0.66364 \\
\hline$r_{7}$ & 0.605467 \\
\hline$r_{10}$ & 0.605026 \\
\hline$r_{9}$ & 0.533097 \\
\hline$r_{13}$ & 0.511176 \\
\hline$r_{8}$ & 0.505172 \\
\hline$r_{12}$ & 0.49921 \\
\hline$r_{11}$ & 0.448455 \\
\hline$r_{15}$ & 0.43197 \\
\hline$r_{14}$ & 0.407712 \\
\hline$r_{16}$ & 0.376078 \\
\hline$r_{18}$ & 0.353758 \\
\hline$r_{17}$ & 0.348983 \\
\hline$r_{19}$ & 0.340352 \\
\hline$r_{22}$ & 0.243988 \\
\hline$r_{21}$ & 0.240664 \\
\hline$r_{20}$ & 0.237701 \\
\hline$r_{23}$ & 0.181768 \\
\hline
\end{tabular}

\section{Conclusions}

In this paper we presented a novel scientometric method for highlighting the researchers' scientific merit based on an evaluation and ranking algorithm. The model combines the following three MADM methods: ONICESCU, DEMATEL and MAUT in a very effective manner so to ensure a clear researchers' raking based on their scientific merit. Compared to the classic DEMATEL method, our algorithm has the merit of including decision makers' weights in the analysis. Influences domains by sub-intervals of $(0,1,2,3,4)$ integer numbers interval were also considered.

Although the algorithm was applied on a fictive research institute, we are confident that the model can easily be adapted to a large number of cases, both research institutes and universities. Thus, although the set of attributes considered in this case was minimal, it can be extended according to real circumstances in order to solve a broad variety of real applications.

\section{REFERENCES}

1. ANDREICA, M., C. RESTEANU, R. TRANDAFIR, Parallel and Distributed Software Assessment in Multi-Attribute Decision Making Paradigm, Studies in Informatics and Control, vol. 23, Issue 2, 2014, pp. 133-142.

2. DYER, J. S., MAUT - Multiattribute Utility Theory. Springer New York. Multiple Criteria Decision Analysis: State of the Art Surveys, 2005 pp. 265-292.

3. DYER, J. S., P. C. FISHBURN, R. E. STEUER, J. WALLENIUS, S. ZIONTS (1992). Multiple Criteria Decision Making, Multi-Attribute Utility Theory: The next ten years, Management Science, Vol. 38, No. 5, pp. 645-654.

4. FISHBURN, P. C., Utility Theory for Decision Making. Huntington, NY. Robert E. Krieger Publishing Co., 1970. ISBN 978-0-471-26060-8.

5. FONTELA, E., A. GABUS, DEMATEL, Innovative Methods, Technical report no. 2, Structural analysis of the world problematique, Battelle Geneva Research Institute, 1974.

6. LEE, H. S., G. H. TZENG, W. YEIH. Y. J. WANG, S. C. YANG, Revised DEMATEL: Resolving the Infeasibility of DEMATEL, Applied 
Mathematical Modelling 34, Elevier, 2013, ISSN: 0307-904X.

7. MATEO, J. R. S. C., Multi-attribute Utility Theory, In: Multi Criteria Analysis in the Renewable Energy Industry. Springer, 2012, p. 63-72.

8. NALIMOV, V. V., Z. M. MULCHENKO, Наукометрия, Изучение развития науки как информационного процесса, Moscow: Nauka, 1969, p. 191.

9. ONICESCU, O., Procedee de estimare comparativă a unor obiecte purtătoare de mai multe caracteristici, Revista de Statistică, no. 4, 1970 (in Romanian).

10. TZENG, G. H., J. J. HUANG, Multiple Attribute Decision Making: Methods and Applications, Chapman \& Hall, CRC Press, 2011, ISBN: 1439861579, 9781439861578.

11. YOON, K. P., C. L. HWANG, Multiple Attribute Decision Making: An Introduction, SAGE Publications, 1995. 